\title{
Осаждение пленок кремния, легированных бором и фосфором газоструйным плазмохимическим методом
}

\author{
(C) В.Г. Щукин, Р.Г. Шарафутдинов, В.О. Константинов
}

Институт теплофизики им. С.С. Кутателадзе Сибирского отделения Российской академии наук, 630090 Новосибирск, Россия

๑ E-mail: konstantinov@itp.nsc.ru

(Получена 22 мая 2018 г. Принята к печати 25 июня 2018 г.)

С использованием диборана и фосфина в качестве легирующих газов методом газоструйного плазмохимического осаждения с применением электронного пучка были получены легированные пленки кремния. Исследовано влияние концентрации легирующего газа, добавки фторсодержащего газа и фонового давления на проводимость и кристаллическую структуру кремниевых слоев. Получены легированные бором аморфные пленки $(a-\mathrm{Si}: \mathrm{H})$ с проводимостью до $5.2 \cdot 10^{-3}(\mathrm{OM} \cdot \mathrm{cm})^{-1}$, при легировании фосфором получены микрокристаллические пленки кремния $(m c-\mathrm{Si}: \mathrm{H})$, имеющие кристалличность до $70 \%$ и значения проводимости на уровне $1(\mathrm{OM} \cdot \mathrm{cm})^{-1}$.

DOI: $10.21883 /$ FTP.2019.01.47000.8917

\section{1. Введение}

В настоящее время гидрогенизированные пленки микрокристаллического кремния $(m c-\mathrm{Si}: \mathrm{H})$ привлекают большое внимание благодаря возможности их применения как в однопереходных тонкопленочных солнечных элементах [1-3], так и в тандемных, называемых „микроморфными“ [4,5], а также в трехпереходных элементах, имеющих наибольшее значение кпд, которое составляет 14\% [6]. Как правило, тонкие пленки микрокристаллического кремния осаждают с использованием методов PE CVD (plasma enhanced chemical vapor depositon) и HWCVD (hot-wire chemical vapor deposition) при температурах подложки около $300^{\circ} \mathrm{C}[7,8]$. Однако при формировании структуры солнечного элемента такие высокие температуры осаждения могут приводить к повреждению и изменению свойств других слоев этой структуры. Поэтому задача низкотемпературного осаждения легированных слоев кремния с высокой проводимостью является актуальной. Для применения в структуре солнечного элемента важно изучать свойства очень тонких легированных слоев $m c-\mathrm{Si}: \mathrm{H}(<50$ нм), в том числе нанесенных на слои $a-\mathrm{Si}: \mathrm{H}$ или $m c-\mathrm{Si}: \mathrm{H}$. Это связано с тем, что кристалличность $m c-\mathrm{Si}: \mathrm{H}$ зависит как от толщины пленки [9], так и от кристаллических свойств подслоя, на котором она осаждается [10]. В настоящей работе получены легированные бором и фосфором тонкие слои кремния при температурах на уровне $200^{\circ} \mathrm{C}$, изучена их кристаллическая структура и измерена их проводимость.

\section{2. Экспериментальная установка и методика}

Эксперименты проводились на газодинамической установке низкой плотности Института теплофизики СО РАН. Схема экспериментальной установки приведена на рис. 1.
В качестве генератора плазмы использовался холодный плазмотрон, состоящий из электронной пушки $1 \mathrm{c}$ полым катодом, с помощью которой формировался пучок электронов, и соплового блока 2, представляющего систему кольцевых сопел Лаваля. Электродная конфигурация разрядной системы электронной пушки включала в себя полый катод 3 , анод 4 и вытягивающий электрод 5 (экстрактор). Электронный пучок 6 формировался путем приложения потенциала к экстрактору относительно анода [11]. Кремнийсодержащий газ (моносилан, $\left.\mathrm{SiH}_{4}\right)$ и легирующие газы (5\% фосфина в водороде, $\mathrm{PH}_{3}+\mathrm{H}_{2}$, и $3 \%$ диборана в аргоне, $\left.\mathrm{B}_{2} \mathrm{H}_{6}+\mathrm{Ar}\right)$ подавались в реакционную вакуумную камеру 7 с помощью системы сопел в виде сверхзвуковой струи 8. При взаимодействии молекул струи газа с электронным пучком образовывалась низкотемпературная электронно-пучковая плазма высокой плотности, содержащая химически активные частицы. Частицы, достигнув подложек 9, размещенных на нагревателе 10, формировали пленку кремния [12].

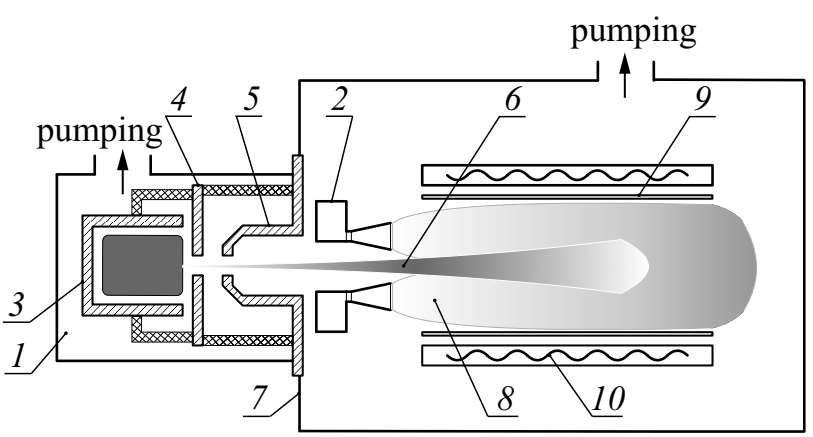

Рис. 1. Схема экспериментальной установки: 1 - электронная пушка с полым катодом, 2 - сопловой блок, 3 - полый катод, 4 - анод, 5 - вытягивающий электрод (экстрактор), 6 - электронный пучок, 7 - реакционная вакуумная камера, $8-$ сверхзвуковая струя газа, $9-$ подложки, $10-$ нагреватель. 
В данной работе представлены результаты экспериментов по осаждению легированных тонких пленок кремния. Для нахождения оптимальных значений степени кристалличности $\left(X_{c}\right)$ и проводимости $(\sigma)$ легированных пленок кремния параметры газоструйного плазмохимического метода осаждения изменялись в следующих диапазонах: ток пучка от 100 до 200 мА, расход моносилана от 60 до $200 \mathrm{sccm}$ ( sccm - нормальный сантиметр кубический в минуту, т.е. сантиметр кубический газа при нормальных условиях - температуре $T=273 \mathrm{~K}$, давлении $p=101325$ Па), расход тетрафторида кремния от 0 до $10 \mathrm{sccm}$, расход фосфина от 0 до $40 \mathrm{sccm}$, расход диборана от 0 до $50 \mathrm{sccm}$. Давление в вакуумной камере в зависимости от расхода аргона поддерживалось на уровне от 2 до 17 Па.

Определение степени кристалличности осажденных слоев кремния проводилось с помощью обработки спектров комбинационного рассеяния света (КРС). Для работы использовался спектрометр с тройным монохроматором Т64000 производства компании Horiba Jobin Yvon. Для получения данных о кристалличности спектр КРС раскладывали на три гауссовых пика [13], а при малых значениях степени кристалличности использовали метод вычитания спектра аморфной фазы [14]. Проводимость определялась четырехзондовым методом с использованием микровольтамперметра Ф-138. Толщины пленок измерялись на сканирующем эллипсометре ЛЭФ-81 „Микроскан“ и по спектрам отражения в ближней инфракрасной области (800-2000 нм) на спектрофотометре UV-3101 PC Shimadzu.

\section{3. Результаты эксперимента и обсуждение}

Как известно [15], кристаллический кремний легче поддается легированию. Ранее было показано [12], что аргон, используемый в качестве газа-носителя, способствует образованию кристаллической фазы в осаждаемых пленках кремния. Во всех экспериментах энергия первичного пучка электронов составляла 600 эВ, расход газа носителя аргона $12 \mathrm{slm}$ ( $\mathrm{slm}$ - нормальный литр в минуту, т.е. литр газа при нормальных условиях температуре $T=273 \mathrm{~K}$, давлении $p=101325$ Па), температура подложки $200^{\circ} \mathrm{C}$. Таким образом, при выбранных условиях на значительной части по длине образца осаждается материал, состоящий из аморфной и кристаллической фаз, со степенью кристалличности $\sim 0.5$. Варьируемые условия экспериментов представлены в таблице.

На рис. 2 проводится сравнение спектров КРС слоя собственного полупроводника, а также пленок кремния, легированных бором и фосфором. Видно, что в спектре нелегированного слоя присутствуют вклады двух фаз - аморфной и кристаллической, в то время как небольшая добавка легирующего газа бора привела к аморфизации пленки $p$-типа проводимости. Легирование

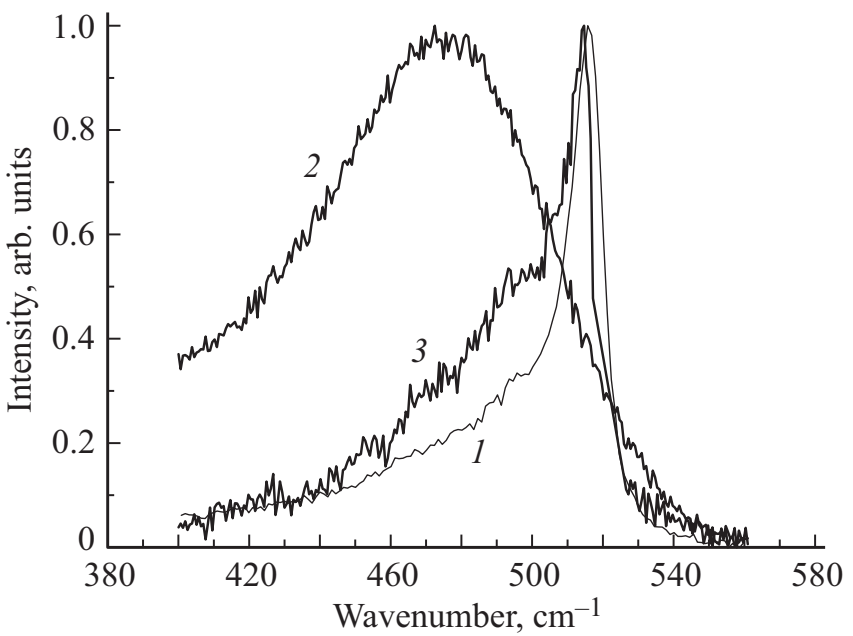

Рис. 2. Спектры комбинационного рассеяния света: 1 - пленка собственного полупроводника, 2 - пленка кремния, легированная бором, 3 - пленка кремния, легированная фосфором.

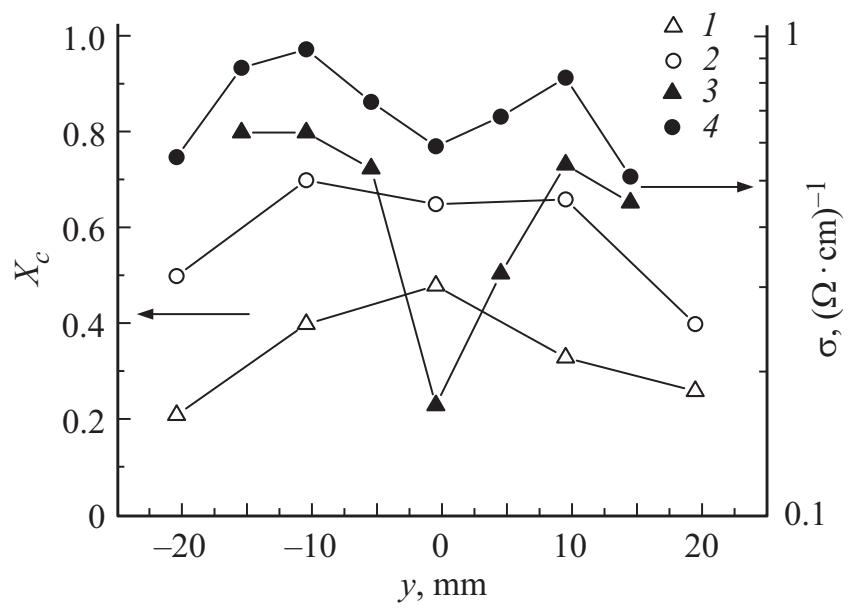

Рис. 3. Зависимости степени кристалличности $(1,2)$ и темновой проводимости $(3,4)$ от поперечной координаты $y$ : $G\left(\mathrm{SiF}_{4}\right)=0(1,3)$ и $5 \mathrm{sccm}(2,4)$.

фосфором практически не изменило соотношение между кристаллической и аморфной фазами.

На рис. 3 приведены поперечные (координата $y$ ) профили значений степени кристалличности и проводимости для пленок кремния, легированных фосфором, в зависимости от расхода тетрафторида кремния $G\left(\mathrm{SiF}_{4}\right)$, полученных в режиме I из таблицы.

Сравнение степени кристалличности пленок кремния, легированных фосфором, полученных в данной работе, и пленок собственного полупроводника, осажденных в аналогичных условиях [16], показывает, что добавка фосфина практически не повлияла на значения $X_{c}$, как видно из рис. 2. Сопоставление данных по кристалличности легированных пленок со значениями их проводимости показывает, что имеется корреляция, при которой пленки с большей кристалличностью имеют 
Условия экспериментов

\begin{tabular}{c|c|c|c|c|c|c}
\hline Режим & I(beam), мА & $P$, Па & $G\left(\mathrm{SiH}_{4}\right), \mathrm{sccm}$ & $G\left(\mathrm{SiF}_{4}\right), \mathrm{sccm}$ & $G\left(\mathrm{PH}_{3}\right), \mathrm{sccm}$ & $G\left(\mathrm{~B}_{2} \mathrm{H}_{6}\right), \mathrm{sccm}$ \\
\hline I & 100 & 17 & 60 & От 0 до 5 & 40 & - \\
II & 150 & 7 & 200 & - & - & От 6 до 40 \\
III & 200 & От 2 до 14.5 & 60 & 10 & - & - \\
IV & 100 & От 6.5 до 14.5 & 100 & - & - & 50
\end{tabular}

Примечание. I(beam) - ток первичного пучка электронов, $G$ - расход газа, $P$ - фоновое давление в реакционной камере

бо́льшую проводимость. Подобное поведение мы наблюдали ранее при исследовании нелегированных слоев кремния [12], причем зависимость проводимости от степени кристалличности очень сильная и может быть объяснена в рамках теории протекания как связанная с формированием перколяционных кластеров, меняющих механизм переноса заряда [16].

Изменение степени кристалличности, от которой, как показано выше, сильно зависит проводимость, в нашем случае может быть достигнуто либо уменьшением концентрации моносилана в газе-носителе, либо добавкой к реакционной смеси тетрафторида кремния. Эти приемы изменения степени кристалличности хорошо известны и широко используются другими авторами $[17,18]$. Малая добавка тетрафторида кремния приводит к существенному увеличению степени кристалличности образца и выравниванию значений проводимости по его поверхности. Увеличение степени кристалличности вызвано тем, что ионы фтора, образующиеся в результате плазмохимических реакций в газовом потоке, участвуют в процессах травления пленки, в первую очередь аморфной фазы кремния. В ходе осаждения пленок кремния, выполняемых с добавкой тетрафторида кремния, поверхность образца подвергается интенсивному ионному травлению, вызванному наличием ионов фтора, в результате чего скорость роста пленки определяется балансом между осаждением и травлением. Это является основным отличием фторидного процесса от моносиланового, в котором ионы и радикалы, образованные в результате активации моносилана, не участвуют в процессах травления. Помимо этого ионы фтора в процессе осаждения способствуют ионной бомбардировке поверхности растущей пленки, что приводит к образованию микрокристаллической структуры. Также ионы $\mathrm{F}$ заменяют слабые связи $\mathrm{Si}-\mathrm{H}$ на прочные $\mathrm{Si}-\mathrm{F}$, образуют связи $\mathrm{Si}-\mathrm{Si}$. Все это приводит к образованию более ,Плотных“ пленок кремния, которые имеют хорошие оптоэлектонные характеристики и меньше подвержены влиянию эффекта Стеблера-Вронски. Также было отмечено [18], что присутствие тетрафторида кремния в процессе осаждения позволяет снизить температуру, необходимую для образования микрокристаллических слоев кремния, в сравнении с силановой плазмой.

На рис. 4 представлены значения проводимости для пленок кремния, легированных бором, в зависимости от расхода диборана, полученных в режиме II из таблицы.

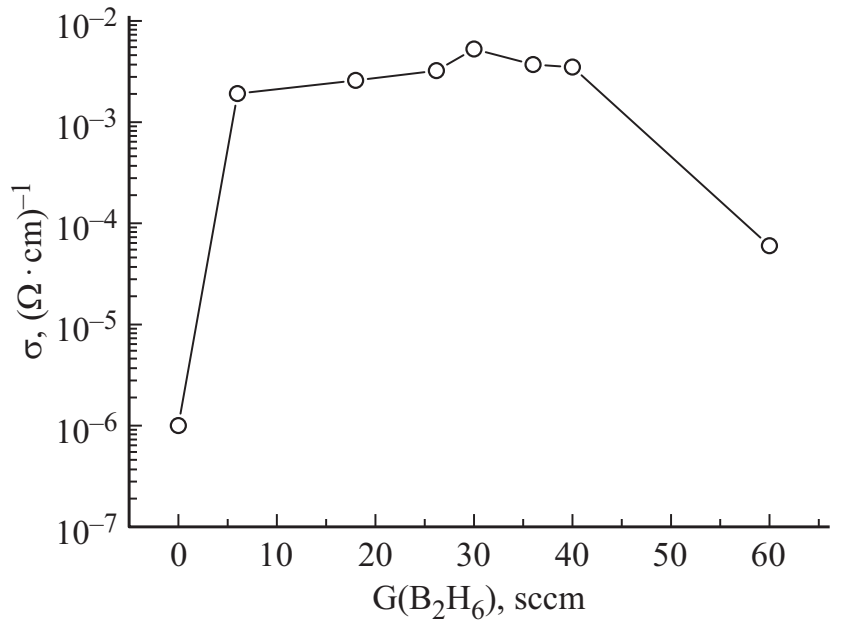

Рис. 4. Зависимость величины темновой проводимости пленок кремния, легированных бором, от расхода диборана.

Как можно видеть, при малой добавке диборана значения проводимости пленки резко возрастают, затем достигает максимума и при высоких концентрациях легирующей примеси наблюдается ее снижение. Такое поведение отмечается многими авторами $[19,20]$. Начальное увеличение проводимости, как правило, вызвано изменением ее механизма, где атомы бора играют важнейшую роль. После достижения максимума наблюдаемое падение значений проводимости авторы работы [19] связывают с изменением структуры пленки кремния с микрокристаллической на аморфную. В нашем случае, судя по низким значениям проводимости и данным рамановской спектроскопии (рис. 2), аморфизация пленки происходит уже при малых добавках диборана. Поэтому характер изменения проводимости связан, по-видимому, с изменением способа, которым атомы бора встраиваются в структуру кремниевой пленки. При увеличении концентрации бора помимо связей $\mathrm{B}-\mathrm{Si}$ происходит образование за счет пассивации бора водородом электрических нейтральных групп В-H и B-H-Si [21], что приводит к снижению проводимости легированных пленок кремния.

На рис. 5,6 приведены продольные (координата $x$ ) профили величины проводимости пленок кремния, легированных фосфором и бором, в зависимости от фонового давления, полученные в режимах III и IV из таблицы соответственно. Как видно из рисунков, в обоих вари- 


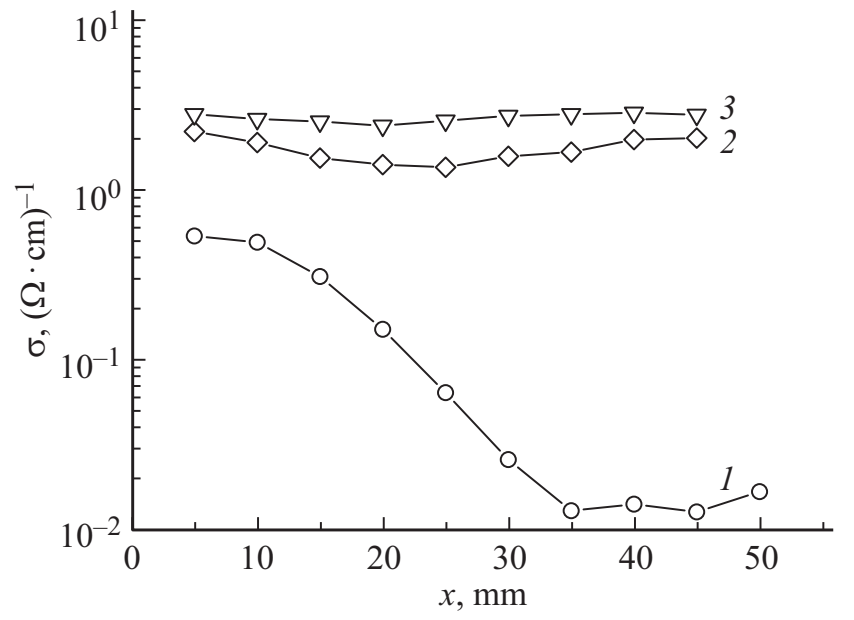

Рис. 5. Влияние фонового давления $P$ на продольный профиль величины проводимости пленок кремния, легированных фосфором. $P$, Па: $1-2,2-13,3-14.5$.

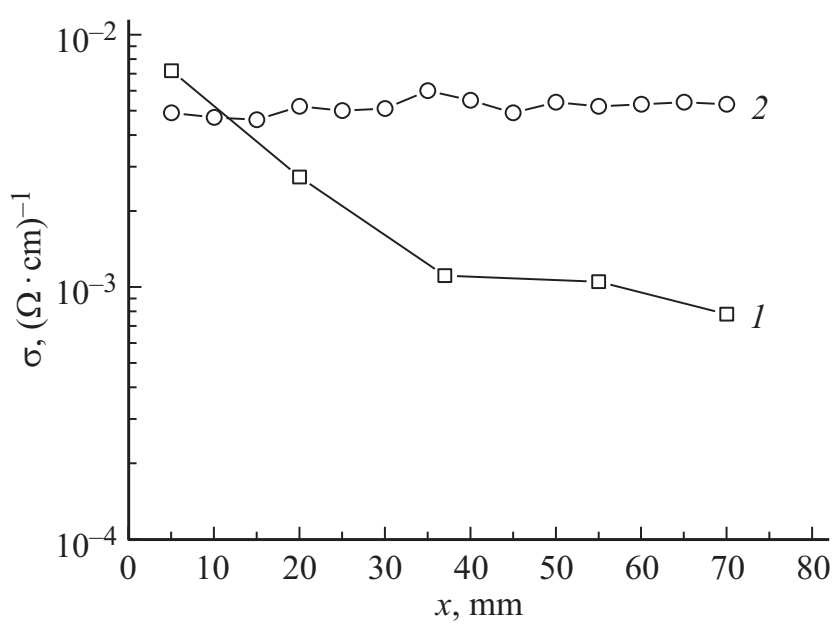

Рис. 6. Влияние фонового давления $P$ на продольный профиль величины проводимости пленок кремния, легированных бором. P, Па: $1-6.5,2-14.5$.

антах при увеличении фонового давления происходит рост проводимости пленок, а также уменьшается ее неравномерность вдоль образца.

Качественно одинаковое влияние фонового давления на зависимость проводимости вдоль образца предполагает общую причину, приводящую к подобному эффекту. Этой общей причиной может быть изменение параметров газового потока под влиянием изменения фонового давления. Согласно данным из работ [22-25], при постоянном расходе газа через сопло увеличение фонового давления приводит к обжиманию струи, уменьшению ее поперечных размеров и большей равномерности газодинамических параметров на ее границах, вплоть до условий, когда все газодинамические параметры вдоль границы струи станут такими же, как в покоящемся газе при истечении в затопленное пространство. Моделирование процесса осаждения, выполненное в [26], показывает, что скорость осаждения определяется потоком частиц вблизи поверхности и, если эти потоки становятся одинаковыми, можно ожидать одинаковых характеристик пленок, в частности одинаковых величин проводимости.

\section{4. Заключение}

При легировании фосфором пленок кремния, полученных газоструйным плазмохимическим осаждением, увеличение степени кристалличности пленок способствует увеличению проводимости. Добавление фосфина в исходную аргон-моносилановую смесь не изменяет изначально заданную степень кристалличности, определяемую величиной расхода аргона. Дополнительное введение тетрафторида кремния увеличивает как степень кристалличности, так и проводимость тонких пленок кремния.

В случае легирования пленок кремния бором малая добавка диборана приводит к аморфизации пленки, вплоть до исчезновения кристаллической фазы. Как следствие, проводимость пленок, легированных бором, значительно ниже, чем пленок, легированных фосфором.

Увеличение фонового давления приводит к увеличению проводимости пленок кремния, а также существенно уменьшает ее неравномерность вдоль образца.

Работа выполнена за счет средств, полученных от ФАНО России (проект гос. рег. 01201350443 „Фундаментальные теплофизические проблемы при росте кристаллов и пленок“).

\section{Список литературы}

[1] J. Meier, R. Fluckiger, H. Keppner, A. Shah. Appl. Phys. Lett., 65, 860 (1994).

[2] A. Gordijn, J.K. Rath, R.E.I. Schropp. Progr. Photovolt.: Res. Appl., 14, 305 (2006).

[3] K. Yamamoto, A. Nakajima, M. Yoshimi. Sol. Energy, 77, 939 (2004).

[4] J. Meier, S. Dubail, A. Shah. Sol. Energy Mater. Solar Cells, 74, 457 (2002).

[5] J.E. Hoetzel, O. Caglar, J.S. Cashmore, C. Goury, J. Kalas, M. Klindworth, M. Kupich, G.-F. Leu, M.-H. Lindic, P.A. Losio, T. Mates, B. Mereu, T. Roschek, I. Sinicco. Sol. Energy Mater. Solar Cells, 157, 178 (2016).

[6] H. Sai, T. Matsui, K. Matsubara. Appl. Phys. Lett., 109, 183506 (2016).

[7] C. Das, A. Dasgupta, S.C. Saha, S. Ray. J. Appl. Phys., 91, 9401 (2002).

[8] S. Klein, F. Finger, R. Carius, H. Wagner, M. Stutzmann. Thin Sol. Films, 395, 305 (2001).

[9] B. Drevillon, C. Godet, S. Kumar. Appl. Phys. Lett., 50, 1651 (1987).

[10] K. Ikuta, Y. Toyoshima, S. Yamasaki, A. Matsuda, K. Tanaka. J. Non-Cryst. Sol., 198-200, 863 (1996).

[11] В.Г. Щукин, В.О. Константинов, В.С. Морозов. ЖТФ, 6, 914 (2018). 
[12] R.G. Sharafutdinov, S.Ya. Khmel, V.G. Shchukin, M.V. Ponomarev, E.A. Baranov, A.V. Volkov, O.I. Semenova, L.I. Fedina, P.P. Dobrovolsky, B.A. Kolesov. Sol. Energy Mater. Solar Cells, 89, 99 (2005).

[13] D. Das, M. Jana, A.K. Barua, S. Chattopadhyay, L.C. Chen, K.H. Chen. Jpn. J. Appl. Phys., 41, 229 (2002).

[14] C. Smit, R.A.C.M.M. van Swaaij, H. Donker, A.M.H.N. Petit, W.M.M. Kessels, M.C.M. van de Sanden. J. Appl. Phys., 94, 3582 (2003).

[15] Y. Baojie, G. Yue, X. Xu, J. Yang, S. Guha. Phys. Status Solidi A, 207, 671 (2010).

[16] R.G. Sharafutdinov, V.G. Shchukin, O.I. Semenova. Inorg. Mater., 48, 445 (2012).

[17] T. Kamei, P. Stradins, A. Matsuda. Appl. Phys. Lett., 74, 1707 (1999).

[18] S. Ray, S. Mukhopadhyay, S.C. Saha, S. Hazra. Thin Sol. Films, 337, 7 (1999).

[19] E. Fathia, Y. Vygranenko, M. Vieirab, A. Sazonov. Appl. Surf. Sci., 257, 8901 (2011).

[20] S. Juneja, S. Sudhakar, J. Gope, K. Lodhi, M. Sharma, S. Kumar. J. Alloys Comp., 643, 94 (2015).

[21] K. Shrestha, V.C. Lopes, A.J. Syllaios, C.L. Littler. J. NonCryst. Sol., 403, 80 (2014).

[22] Р.Г. Шарафутдинов, В.В. Волчков, А.И. Иванов, А.К. Ребров, Н.И. Кисляков. ПМТФ, № 2, 64 (1973).

[23] А.К. Ребров, С.Ф. Чекмарев, Р.Г. Шарафутдинов. ПМТФ, № 1, 136 (1971).

[24] Р.Г. Шарафутдинов, Н.И. Кисляков, А.К. Ребров. ПМТФ, № 2, 42 (1975).

[25] А.К. Ребров, Н.И. Кисляков, Р.Г. Шарафутдинов. ПМТФ, № 1, 121 (1973).

[26] P.A. Skovorodko, R.G. Sharafutdinov, V.G. Shchukin, V.O. Konstantinov. AIP Conf. Proc., 1501, 1437 (2012).

Редактор Л.В. Шаронова

\section{Deposition of silicon films doped with boron and phosphorus, by gas-jet plasma-chemical method}

V.G. Schukin, R.G. Sharafutdinov, V.O. Konstantinov

Kutateladze Institute of Thermophysics,

Russian Academy of Sciences,

630090 Novosibirsk, Russia 